\title{
Electrooxidation of Reformate Gases at Model Anodes
}

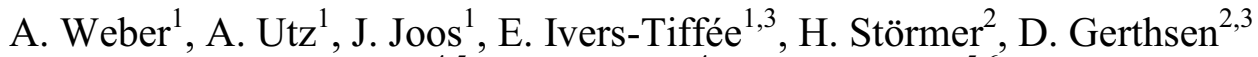 \\ V. Yurkiv ${ }^{4,5}$, H.-R. Volpp ${ }^{4}$, W. G. Bessler ${ }^{5,6}$ \\ ${ }^{1}$ Institut für Werkstoffe der Elektrotechnik (IWE) \\ ${ }^{2}$ Laboratorium für Elektronenmikroskopie (LEM) \\ ${ }^{3}$ DFG Center for Functional Nanostructures (CFN) \\ Karlsruher Institut für Technologie (KIT), D-76131 Karlsruhe, Germany \\ ${ }^{4}$ Institute of Physical Chemistry, Heidelberg University, Heidelberg, Germany \\ ${ }^{5}$ German Aerospace Centre (DLR), Institute of Technical Thermodynamics \\ Stuttgart, Germany \\ ${ }^{6}$ Institute of Thermodynamics and Thermal Engineering (ITW), Universität Stuttgart \\ Stuttgart, Germany
}

This paper summarizes the experimental and modeling results concerning the electrooxidation of hydrogen and carbon monoxide, the main oxidizable compounds in reformates, at patterned nickel anodes on polycrystalline yttria stabilized zirconia electrolytes. The line specific resistance of the three phase boundary was evaluated within a wide range of gas compositions and temperature. The investigations showed that microstructural stability, impurities, accelerated degradation and reversible dynamic changes are key issues which have to be considered. Elementary kinetic models, parameterized with literature data, temperature-programmed desorption and reaction and quantum chemical calculation results were in excellent agreement with the experimental data. For the first time it could be shown that the line specific resistance values evaluated by means of patterned anodes are applicable in homogenized and space resolved models for cermet anodes.

\section{Introduction}

In order to allow experimentally and theoretically more detailed investigations of the electrochemical processes at the three phase boundary (TPB), various types of model anodes as micropatterned, point and mesh type electrodes have been used (1-6). These systems are expected to have geometrically well-defined active surfaces and two- and three-phase boundaries. Furthermore there is no complex coupling of TPB-reactions, gas diffusion and bulk transport as it is unavoidable in technical anode structures (7). Still, numerous studies have shown the high complexity of the electrochemical behavior of these geometrically simple systems. In order to allow a mechanistic interpretation of observed electrochemical behavior in terms of reaction pathways and rate-determining steps, anode models have been developed. This includes both atomistic quantum chemical models and mean-field kinetic models. These models allow a detailed assessment of the interaction of charge-transfer reactions with surface and bulk transport in the geometrically confined regions of the model electrode.

Model anodes are characterized by their well-defined microscale geometry. For patterned anodes, metal patterns are photolithographically applied on a solid electrolyte 
substrate. This technique allows well-defined contact areas and high TPB lengths $1_{\text {TPB }}$. Preparation can either be realized by metal etching or metal liftoff, as described in $(8,9)$. Metal thickness varies from $0.1-2 \mu \mathrm{m}$, with pattern widths in the range of 5-50 $\mu \mathrm{m}$. This results in absolute TPB lengths in the range of $1_{\mathrm{TPB}}=1 \ldots 10 \mathrm{~m}$ within a $1 \mathrm{~cm}^{2}$ electrode.

Electrochemical characterization of patterned anodes is usually performed by IVcharacteristics and electrochemical impedance spectroscopy. The latter is a powerful tool to separate individual electrode processes. The variation of parameters as gas composition, temperature and polarization voltage provides information about parameter dependencies and should enable us to determine the physical origin of the electrode processes. Several studies exist for the characterization in $\mathrm{H}_{2}-\mathrm{H}_{2} \mathrm{O}$ atmosphere (1-6), while literature on the characterization in $\mathrm{CO}-\mathrm{CO}_{2}$ atmosphere is sparse $(5,10,11)$. Despite of the well-defined geometry, the analysis of results from electrochemical characterization of patterned anodes in $\mathrm{H}_{2}-\mathrm{H}_{2} \mathrm{O}$ anodes revealed strong deviations with respect to absolute line specific resistance (LSR) values as well as parameter dependencies (6), impeding the evaluation of modeling studies of the elementary reaction mechanism. These deviations are potentially caused by instabilities of the Ni thin film (5), impurities at the TPB (12) or errors induced by an inappropriate use of reference electrodes (13). Therefore detailed stability and impurity analyses of patterned anodes are indispensible $(6,14)$.

In order to allow a mechanistic interpretation of observed electrochemical behavior in terms of reaction pathways and rate-determining steps, numerical anode models have been developed. This includes both atomistic quantum chemical models (15) and meanfield kinetic models (16). These models allow a detailed assessment of the interaction of charge-transfer reactions with surface and bulk transport in the geometrically confined regions of the model electrode.

In this paper, our results on experimental and modeling investigations concerning the electrooxidation of the oxidizable compounds $\left(\mathrm{H}_{2}\right.$ and $\left.\mathrm{CO}\right)$ of reformate gases at model anodes are summarized. It will be shown that a careful experimental analysis of model anodes is the basis for a detailed elementary kinetic modeling of TPB reactions as well as for homogenized and spatially resolved models of cermet anodes.

\section{Experimental}

\section{$\underline{\text { Processing of Patterned Ni Anodes }}$}

As pointed out in one of our previous papers (9), there are various methods and procedures to fabricate patterned anodes. In this study results of patterned Ni-anodes deposited on $8.5 \mathrm{~mol} \%$ polycrystalline $\mathrm{Y}_{2} \mathrm{O}_{3}$-stabilized $\mathrm{ZrO}_{2}$ (YSZ) substrates (Itochu Ceratec Corp., Japan) by a lift-off process are discussed. The design of the $800 \mathrm{~nm}$ thick Ni layer was composed of parallel stripes with a width of 8 to $25 \mu \mathrm{m}$, yielding a TPB length between 1 to $8 \mathrm{~m}$. Two stripes at the ends ensure proper contacting of the patterned $\mathrm{Ni}$ anodes. Whereas in previous study no impact of the stripe and spacing width was observed (6), the thickness of $800 \mathrm{~nm}$ is required to ensure the stability of the structure during characterization at temperatures of up to $800{ }^{\circ} \mathrm{C}$ in reducing atmosphere (17). 


\section{Microstructural Characterization}

As discussed in (5) the microstructural stability is a key issue for patterned anodes. Therefore the samples were analyzed by scanning electron microscopy (SEM: Zeiss 1540 $\mathrm{XB})$ before and after electrochemical characterization $(6,18)$. In addition, the TBP and the nickel / YSZ interface of selected samples was analyzed by transmission electron microscopy (TEM: FEI Titan 80-300) to detect impurity phases as described in (19).

\section{$\underline{\text { Impurity Analysis }}$}

In order to assess the impurity composition and concentration on the patterned $\mathrm{Ni}$ anodes, detailed impurity analysis has been performed at Risø DTU National Laboratory for Sustainable Energy by means of Atomic Force Microscopy (AFM: DME Danish Micro Engineering DualScope atomic force microscope), Time-of-Flight Secondary Ion Mass Spectrometry (TOF-SIMS: ION-TOF GmbH, Germany) and X-ray Photoelectron Spectroscopy (XPS: Thermo Fisher Scientific, UK). Details about the analysis procedures are given in $(14,19)$. YSZ-substrates, patterned $\mathrm{Ni}$ anodes after electrochemical characterization and similar samples after removing the Ni electrode in an acidic solution of $\mathrm{HNO}_{3}$ have been investigated. Hence it is possible to assess all regions of interest: i) the YSZ surface, ii) the Ni surface, iii) the electrode-electrolyte interface between YSZ and $\mathrm{Ni}$, and iv) the TPB.

\section{Electrochemical Characterization}

To circumvent the unavoidable distortions of the impedance caused by reference electrodes (13), an electrochemically well defined Ni/8YSZ cermet anode exhibiting an at least 2 orders of magnitude lower polarization resistance was chosen as the counter electrode. The Ni/YSZ counter electrode was screen-printed following the procedure described by Sonn et al. (20). The electrochemical characteristics of this electrode are summarized in the same paper. This counter electrode was applied before preparation of the Ni patterned anodes, as sintering and reduction of this anode require the highest temperatures.

The samples were contacted either by $\mathrm{Ni}$ meshes or a special contact block, an additional weight of $18 \mathrm{~g}$ on top ensures the electrical contact $(6,11)$. The sample holder was then placed in a gastight $\mathrm{Al}_{2} \mathrm{O}_{3}$ chamber where the sample was purged with the appropriate fuel gas composition on both sides. The fuel gas composition was controlled by mass flow controllers with a total gas flow of $100-300 \mathrm{ml} / \mathrm{min} ; \mathrm{N}_{2}$ was used as balance for independent variation of $\mathrm{pH}_{2}, \mathrm{pH}_{2} \mathrm{O}, \mathrm{pCO}$ and $\mathrm{pCO}_{2}$ respectively. High contents of water vapor were realized by feeding oxygen and hydrogen into an upstream combustion chamber. A Nernst probe located near the sample monitors the $\mathrm{pO}_{2}$ and hence provides information about the actual gas composition and possible leakages in the setup, which were very low $(<0.02 \%)$.

For the electrochemical characterization, impedance spectra and current voltage characteristics were recorded over an extended range of gas composition (in $\mathrm{H}_{2}-\mathrm{H}_{2} \mathrm{O}$ atmosphere: $8 \cdot 10^{2} \mathrm{~Pa} \leq \mathrm{pH}_{2} \leq 9 \cdot 10^{4} \mathrm{~Pa}$ and $2 \cdot 10^{1} \mathrm{~Pa} \leq \mathrm{pH}_{2} \mathrm{O} \leq 6 \cdot 10^{4}$, in CO-CO

atmosphere: $4.0 \cdot 10^{2} \mathrm{~Pa} \leq \mathrm{pCO} \leq 5.1 \cdot 10^{4} \mathrm{~Pa}$ and $9.5 \cdot 10^{2} \mathrm{~Pa} \leq \mathrm{pCO}_{2} \leq 9.2 \cdot 10^{4} \mathrm{~Pa}$ ) and temperature $\left(450{ }^{\circ} \mathrm{C} \leq \mathrm{T} \leq 800^{\circ} \mathrm{C}\right)$. The recording of impedance spec tra was performed 
both by a Zahner IM6 and a Solartron $1260 \mathrm{FRA}$, in a frequency range of $100 \mathrm{mHz}-1$ $\mathrm{MHz}$. Due to the high impedance of the patterned anodes voltage stimulus was chosen instead of current stimulus; the amplitude was $10 \mathrm{mV}$.

Our previous study showed that three processes are contributing to the overall impedance response (6): besides the targeted charge transfer process of the Ni patterned anode, contributions of gas diffusion and the counter electrode are detected. For the interpretation of impedance spectra, the same equivalent circuit was used. It consists of three RQ elements in series with additional ohmic contributions of electrolyte and measurement setup and an inductive element accounting for the wiring. The line specific charge transfer resistance LSR $_{\mathrm{ct}}$ was determined by multiplying the charge transfer resistance obtained from an equivalent circuit fit with the actual length of the three phase boundary $1_{\mathrm{TPB}}$ of the sample.

\section{$\underline{\text { Temperature-Programmed Desorption and Reaction }}$}

In order to obtain thermodynamic and kinetic parameters of $\mathrm{CO}$ adsorption/desorption and oxidation on individual $\mathrm{Ni}$ and $\mathrm{YSZ}$ and $\mathrm{H}_{2}$ oxidation on YSZ surfaces temperatureprogrammed desorption (TPD) and temperature-programmed reaction (TPR) experiments were performed under molecular flow conditions in a reaction chamber as described in (21). In the $\mathrm{CO}$ desorption and oxidation studies a Ni(111) single crystal (purity $99.99 \%$ ) was used, which was cleaned by reduction in $\mathrm{H}_{2}$ atmosphere and repeated sputtering $(1 \mathrm{keV})$ cycles followed by annealing cycles, until a sharp (1 $\mathrm{x} 1)$ LEED pattern of the bare Ni surface could be observed. For the $\mathrm{CO}, \mathrm{H}_{2}$ oxidation and $\mathrm{CO}_{2}, \mathrm{H}_{2} \mathrm{O}$ surface dissociation studies on YSZ, a polycrystalline sample $\left(8.25 \mathrm{~mol} \% \mathrm{Y}_{2} \mathrm{O}_{3}\right)$ from Itochu (Tokyo, Japan) was employed.

\section{Modeling}

\section{Quantum Chemical Calculations}

Quantum chemical calculations based on density functional theory (DFT) were performed to investigate $\mathrm{H}_{2}, \mathrm{CO}$ oxidation and $\mathrm{H}_{2} \mathrm{O}, \mathrm{CO}_{2}$ dissociation energetics on YSZ surfaces. The present calculations were performed using the CASTEP (Cambridge Sequential Total Energy Package) code (22) in the framework of the generalized gradient approximation (GGA), as proposed by Perdew et al. (23), in combination with Vanderbilt ultrasoft pseudopotentials (24). In the computations the plane wave basis set was truncated at a kinetic energy of $420 \mathrm{eV}$. The calculations were conducted over a range of k-points within the Brillouin zone as generated by the full Monkhorst-Pack scheme (25) with a $2 \times 2 \times 1$ mesh. The slab used in this study and the possible reaction pathways of $\mathrm{H}_{2}$ and $\mathrm{CO}$ oxidation are described in detail in Ref. (26).

\section{Elementary Kinetic Modeling}

The patterned electrodes were represented in a one-dimensional reaction-diffusion model. The main model assumptions are: i) Electrochemical reactivity is described by elementary kinetics, that is, by resolving single steps that represent chemical reactivity on a molecular scale. The models are thermodynamically consistent by using reversible reactions throughout. ii) The charge-transfer reaction is assumed to be a surface spillover 
reaction taking place at the TPB. iii) Surface diffusion is modeled in one dimension perpendicular to the TPB on the basis of a surface-adapted Fickian diffusion approach. The modeling methodology and mathematical equations are described in detail in (27), the model parameters are given in (8). The detailed model comes at the cost of a large number of model parameters (thermodynamic, kinetic and diffusion coefficients of all surface species and surface reactions). Parameter values are obtained using hierarchical approach (16) by combining literature data (both theoretical and experimental) (27) and our own TPD/TPR experiments and DFT calculations. The kinetic coefficients of the spillover reactions were obtained by fitting to our experimental electrochemical data. All simulations were carried out within the in-house software code DENIS (28).

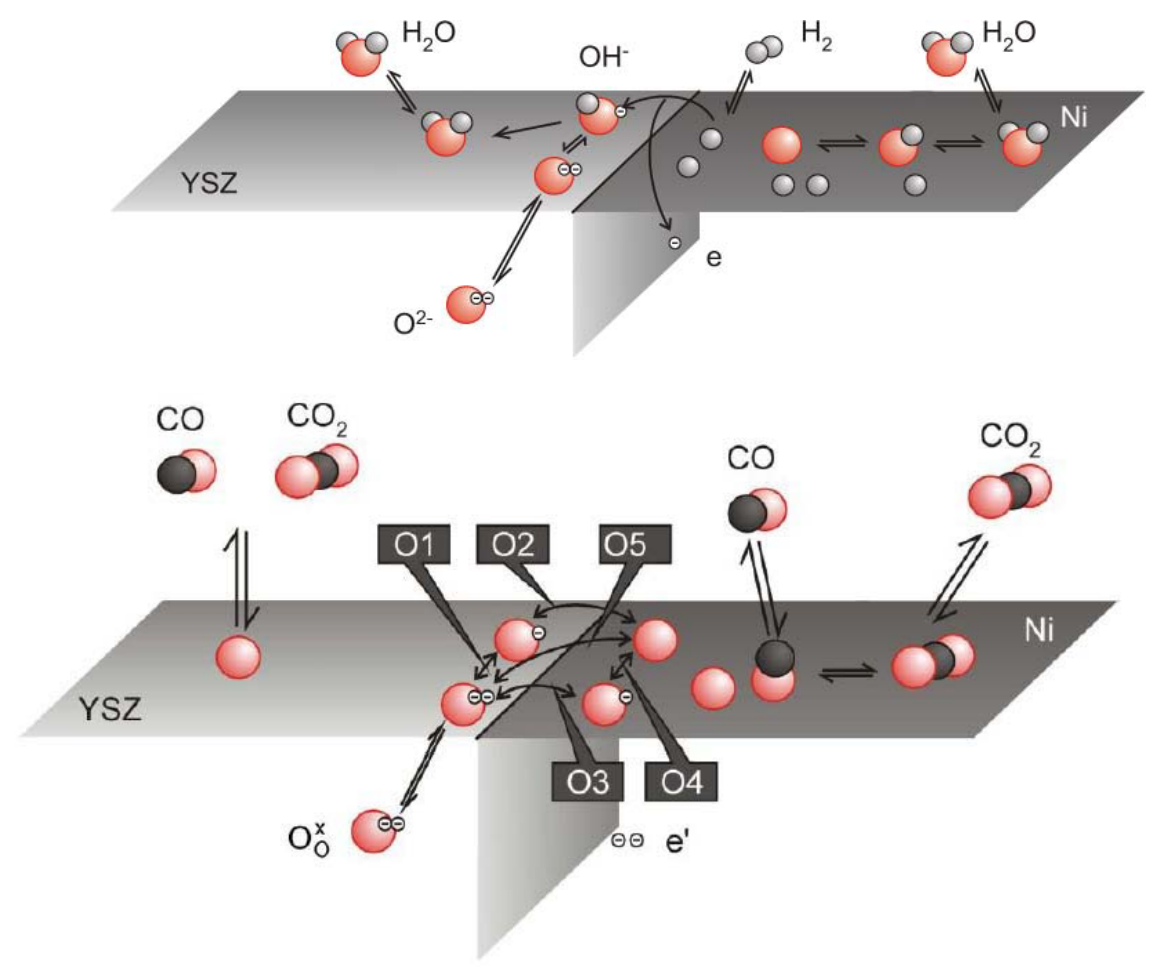

Figure 1. Elementary kinetic mechanisms used in the present work. Upper figure: $\mathrm{H}_{2}$ oxidation via hydrogen spillover pathway. Lower figure: $\mathrm{CO}$ oxidation via combined oxygen spillover and reactive electrolyte pathways.

A number of different spillover scenarios were studied both for $\mathrm{H}_{2}$ oxidation (including hydrogen spillover, oxygen spillover, hydroxyl spillover hydrogen interstitial pathways) and $\mathrm{CO}$ oxidation (including oxygen spillover and reactive electrolyte pathways) (16). In the present paper we show results from selected mechanisms as depicted in Figure 1.

\section{Models for Cermet Anodes}

To compare the electrochemical performance of patterned $\mathrm{Ni}$ anodes and technical $\mathrm{Ni} / 8 \mathrm{YSZ}$ cermet anode, two different models for Ni/YSZ cermet anodes have been parameterized with the $\mathrm{LSR}_{\mathrm{ct}}$-values of patterned nickel anodes evaluated in this study: (i) a homogenized transmission line model from (20),(7) and (ii) a space resolved FEM microstructure model (29). 


\section{Results and Discussion}

Processing and Microstructural Characterization

As pointed out in (6) pre-test SEM analysis showed a perfect pattern, e.g. the stripes exhibited a good adhesion and a straight border, were free of holes and bubbles and no stripes were destroyed or delaminated. Unfortunately these perfect patterns are not stable. During the first $20 \mathrm{~h}$ of thermal exposure at $800{ }^{\circ} \mathrm{C}$ an initial decrease of the resistance by $60 \%$ to an average $\mathrm{LSR}_{\mathrm{ct}}$-value of $54 \Omega \cdot \mathrm{m}$ is observed. SEM studies revealed an increase in $1_{\mathrm{TPB}}$ of $30 \%$ caused by the grain growth and related morphological changes in the $\mathrm{Ni}$ thin film. For the further $\mathrm{LSR}_{\mathrm{ct}}$-calculation, this initial increase in tpb-length was considered by a correction factor $\tau_{\text {corr }}=1.3$. The validity of this factor throughout the hole measurement was confirmed by post test analysis of different samples after several hundred hours of testing (18). During the tests no further grain growth occurred and the pattern neither showed delamination nor island, hole or bubble formation as discussed in $(5,30)$.

The initial $\mathrm{LSR}_{\mathrm{ct}}$-decrease of $60 \%$ during the first $20 \mathrm{~h}$ obviously does not match the increase in $1_{\mathrm{TPB}}$ of $30 \%$. The microstructural changes are responsible for an apparent $\mathrm{LSR}_{\mathrm{ct}}$-decrease of approximately $25 \%$, the remaining $35 \%$ have to be attributed to another reason as for example the impurity content at the TPB.

As the initial microstructural changes are unavoidable and reproducible (6), an initial annealing procedure in the test setup (in our case $24 \mathrm{~h}$ at $800^{\circ} \mathrm{C}$ in $90 \% \mathrm{H}_{2} / 10 \% \mathrm{H}_{2} \mathrm{O}$ ) resulting in a patterned $\mathrm{Ni}$ anode with a sufficient microstructural stability should be considered as the last step in the fabrication procedure. All the $\mathrm{LSR}_{\mathrm{ct}}$-values presented in this paper have been measured after the annealing procedure.

\section{Electrochemical Characterization}

The aim of the electrochemical characterization was to evaluate reproducible LSR $_{\mathrm{ct}}$ values as a function of gas composition and temperature required for elementary kinetic modeling as well as for homogenized and microstructurally resolved modeling of cermet anodes. Our previous studies $(6,17,31)$ showed that next to changes during the initial annealing procedure further dynamic processes with slow settling times have a significant impact on the obtained $\mathrm{LSR}_{\mathrm{ct}}$ values:

- A degradation rate depending on the gas constituents was observed. A value of $0.4 \%$ / $\mathrm{h}$ was determined for a high water vapor content $\left(\mathrm{pH}_{2}=3.9 \cdot 10^{4} \mathrm{~Pa}_{2} \mathrm{pH}_{2} \mathrm{O}\right.$ $=6.210^{4} \mathrm{~Pa}$ ) at $800^{\circ} \mathrm{C}$. In $\mathrm{CO}-\mathrm{CO}_{2}$ atmosphere, a lower degradation rate of $0.18 \%$ was observed. This degradation rate is orders of magnitude higher than the degradation of technical cermet anode structures (32). It is assumed that the degradation is related to an enhanced agglomeration of impurities at the TPB.

- A slow relaxation process after variations of $\mathrm{pH}_{2}$ and $\mathrm{pH}_{2} \mathrm{O}$ was discovered. For $\mathrm{pH}_{2} \mathrm{O}$ variations, settling times are $2 \ldots 3 \mathrm{~h}$ at $800^{\circ} \mathrm{C}$, while $\mathrm{pH}_{2}$ variations necessitate longer settling times of $5 \ldots 8 \mathrm{~h}$ at $800^{\circ} \mathrm{C}$. For $\mathrm{CO}-\mathrm{CO}_{2}$ atmosphere, equilibrium values were attained within a few minutes. Therefore, it is assumed that this behavior is related to variations in hydrogen concentration in the bulk of electrode and electrolyte. 
- A reproducible sequence of fast activation of cell performance during the recording of $\mathrm{CV}$-characteristics followed by a slow relaxation process with settling times of about $20 \mathrm{~h}$ is observable.

In order to assure the reproducibility of characterization results, next to the standardized initial heat treatment, a sufficient delay (several hours) between parameter variation and measurement was applied. The fast degradation of the patterned Ni-anodes was considered by periodical EIS-measurements at fixed operating conditions and an appropriate correction of the results. Hence, this is a significant improvement compared to previous studies on patterned $\mathrm{Ni}$ anodes, which did neither report these dynamic changes, nor specify the entire measurement procedure.

The parameter dependencies of $\mathrm{LSR}_{\mathrm{ct}}$ on $\mathrm{pH}_{2}, \mathrm{pH}_{2} \mathrm{O}, \mathrm{pCO}, \mathrm{pCO}_{2}, \mathrm{~T}$ and polarization voltage $\eta$ have been determined by variation of a single parameter at a time. For the recording of measurement series, sufficient settling times have been applied to assure stable conditions. In addition to the detailed elementary kinetic models, we derived empirical global rate laws from the experiments. The dependencies are described in accordance to Butler-Volmer equation using a power law ansatz for the gas composition dependencies and an Arrhenius-type temperature dependency (6,11). The obtained parameters are summarized in Table I.

$$
\begin{gathered}
\mathrm{LSR}_{\mathrm{ct}}=\mathrm{c}_{1} \cdot\left(\mathrm{pH}_{2, \mathrm{An}}\right)^{-\mathrm{a}} \cdot\left(\mathrm{pH}_{2} \mathrm{O}_{\mathrm{An}}\right)^{-\mathrm{b}} \\
\mathrm{LSR}_{\mathrm{ct}}=\mathrm{c}_{2} \cdot \exp \left(\frac{\mathrm{E}_{\mathrm{act}}}{\mathrm{kT}}\right) \\
\mathrm{LSR}_{\mathrm{ct}}=\mathrm{c}_{3} \cdot(\mathrm{pCO})^{-\mathrm{c}} \cdot\left(\mathrm{pCO}_{2}\right)^{-\mathrm{d}} \\
\mathrm{LSR}_{\mathrm{ct}}=\mathrm{c}_{4} \cdot \exp \left(\frac{\mathrm{E}_{\mathrm{act}, \mathrm{ct}}}{\mathrm{RT}}\right)
\end{gathered}
$$

TABLE I: Comparison of the parameter dependencies a, b, c and d (all at $800{ }^{\circ} \mathrm{C}$ and OCV)

\begin{tabular}{|c|c|c|}
\hline Parameter dependency & Range & $\mathbf{L S R}_{\mathrm{ct}}$ \\
\hline a [-] & $\mathrm{pH}_{2} \mathrm{O}=6.7 \cdot 10^{3} \mathrm{~Pa}:$ & 0.07 \\
\hline $\mathrm{b}[-]$ & $\mathrm{pH}_{2}=9.0 \cdot 10^{3} \mathrm{~Pa}:$ & 0.68 \\
\hline $\mathrm{E}_{\text {act }}\left(\mathrm{H}_{2}-\mathrm{H}_{2} \mathrm{O}\right)[\mathrm{eV}]$ & $\begin{array}{l}700-800^{\circ} \mathrm{C}: \\
450-700^{\circ} \mathrm{C}:\end{array}$ & $\begin{array}{l}1.01 \\
1.37\end{array}$ \\
\hline c [-] & $\begin{array}{l}\mathrm{pCO}_{2}=5.1 \cdot 10^{4} \mathrm{~Pa}: \\
\mathrm{pCO}_{2}=2.0 \cdot 10^{4} \mathrm{~Pa}:\end{array}$ & $\begin{array}{c}0.24 \\
0.11 \text { (kink at } 10^{4} \mathrm{~Pa}:+0.47 \text { to }-0.34 \text { ) }\end{array}$ \\
\hline $\mathrm{d}[-]$ & $\begin{array}{l}\mathrm{pCO}=3.9 \cdot 10^{4} \mathrm{~Pa}: \\
\mathrm{pCO}=1.0 \cdot 10^{4} \mathrm{~Pa}:\end{array}$ & $\begin{array}{c}0.79 \\
0.61\left(\text { kink at } 2 \cdot 10^{4} \mathrm{~Pa}:+0.76 \text { to }+0.42\right)\end{array}$ \\
\hline $\mathrm{E}_{\mathrm{act}}\left(\mathrm{CO}-\mathrm{CO}_{2}\right)[\mathrm{eV}]$ & $700-800^{\circ} \mathrm{C}:$ & 1.42 \\
\hline
\end{tabular}
and $\mathrm{E}_{\text {act }}$ obtained for LSRct of patterned Ni anodes, as reported in our previous studies $(6,11)$. a, $\mathrm{b}, \mathrm{c}$ and $\mathrm{d}$ refer to the dependencies of the resistance on $\mathrm{pH}_{2}, \mathrm{pH}_{2} \mathrm{O}, \mathrm{pCO}$ and $\mathrm{pCO}_{2}$ described by $\mathrm{LSR}_{\mathrm{ct}} \approx \mathrm{pH}_{2}^{-\mathrm{a}} \cdot \mathrm{pH}_{2} \mathrm{O}^{-\mathrm{b}}$ and $\mathrm{LSR}_{\mathrm{ct}} \approx \mathrm{pCO}^{-\mathrm{c}} \cdot \mathrm{pCO}_{2}^{-\mathrm{d}}$ respectively. 
In Figure 6 the major results and dependencies are displayed. The evaluated $\mathrm{LSR}_{\mathrm{ct}}$ values for $\mathrm{H}_{2}-\mathrm{H}_{2} \mathrm{O}$ and $\mathrm{CO}-\mathrm{CO}_{2}$ atmosphere are in the same range, which is in good agreement with our results on cermet anodes $(33,34)$. The difference in $\mathrm{LSR}_{\mathrm{ct}}$ respectively ASR for $\mathrm{H}_{2}$ and $\mathrm{CO}$ electrooxidation is fairly below previously reported values (35),(36). Strong negative dependencies of LSR and $\mathrm{CO}_{2}$ respectively) were observed, whereas the dependencies on the reactants $\left(\mathrm{H}_{2}\right.$ and $\mathrm{CO}$ respectively) are weak. In $\mathrm{CO}-\mathrm{CO}_{2}$ atmosphere, the change in dependency on $\mathrm{pCO}$ at ca. $10^{4} \mathrm{~Pa}$ together with an increase in the activation energy from 0.85 to $1.42 \mathrm{eV}$ is a strong indicator for a change in the reaction mechanism.

The comparison to experimental data with patterned $\mathrm{Ni}$ anodes from other groups showed significant deviations in absolute values of $\mathrm{LSR}_{\mathrm{ct}}$ of up to two orders of magnitude (6), whereas the comparison to point anodes shows weaker deviations within one order of magnitude. This emphasizes the importance of (i) avoidance of impurities and (ii) consideration of dynamic anode processes during the electrochemical characterization.

\section{$\underline{\text { Impurity Analysis }}$}

Whereas the investigation of patterned anodes after electrochemical testing $(>200 \mathrm{~h}$ @ $800{ }^{\circ} \mathrm{C}$ ) by TEM revealed no impurity agglomeration at the TPB (Figure 3), SEM analysis showed nanoscaled imprints on the electrolyte surface close to the TPB (Figure 3). Compared to the $\mathrm{SiO}_{2}$-based impurity ridges discussed in literature (37), which exhibited a height of up to several $\mu \mathrm{m}$, the "impurity imprints" in our study were orders of magnitude smaller.
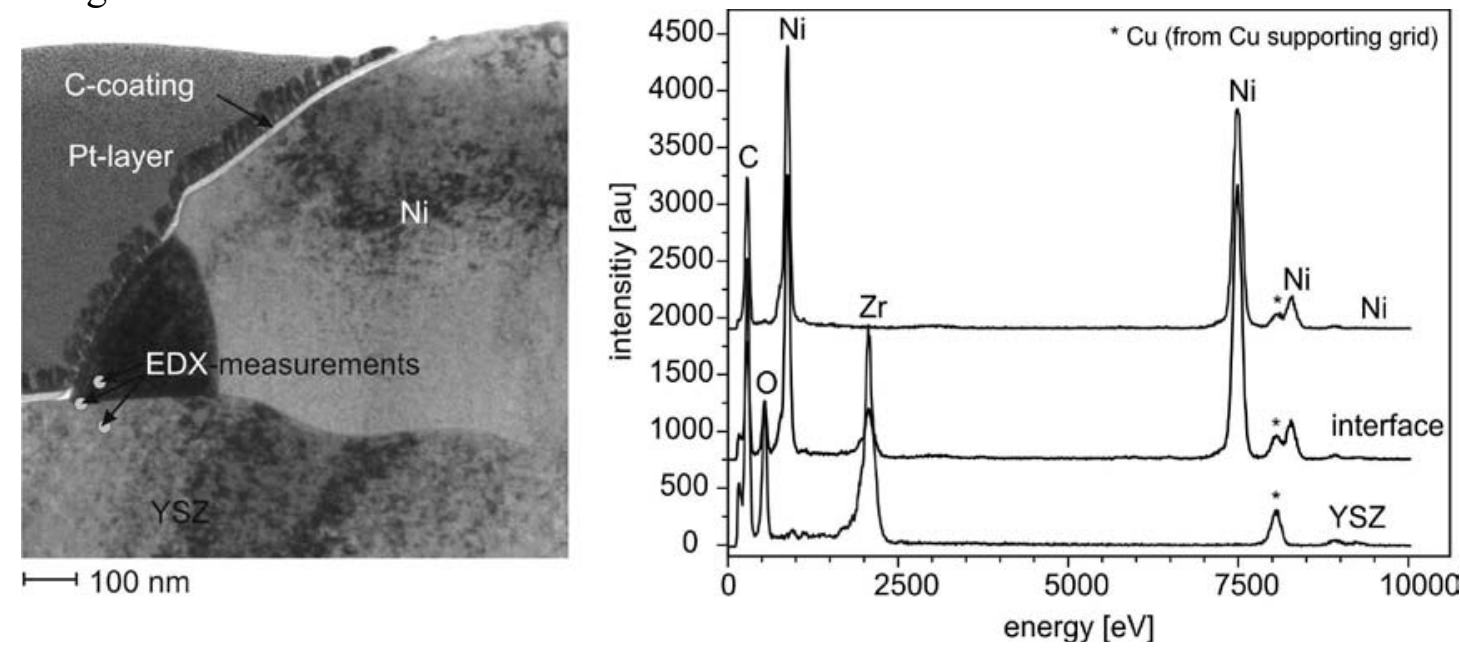

Figure 2. TEM cross section image of the TPB; the EDX measurements at the TPB showed the existence of nickel, yttria and zirconia only.

The "impurity imprints" observed in the SEM were confirmed by the AFM analysis. The height was in the range of 8 to $15 \mathrm{~nm}$. Each individual imprint is about 10 to $30 \mathrm{~nm}$ wide, whereas the whole area covered by these imprints did not exceed $2 \mu \mathrm{m}$. A space resolved chemical analysis of the imprints, with a height of less than 40 atomic layers (assuming that the impurity consists of $\mathrm{SiO}_{2}$ ), was not possible so far. The TOF-SIMS and XPS analysis only provide space resolutions of several $100 \mathrm{~nm}$ and several $100 \mu \mathrm{m}$ respectively. Therefore no information about the composition of the imprints is available 
up to now. The TOF-SIMS analysis (Figure 4) shows the lateral distribution of the main impurities. It is obvious, that there is no detectable enrichment of $\mathrm{SiO}_{2}$ at the TPB but $\mathrm{Ca}$ and $\mathrm{Mg}$ show an increase in intensity close to the Ni electrode. This might indicate species accumulation at the impurity imprints, however the lateral extension of approximately $4 \mu \mathrm{m}$ is rather large compared to $1 \ldots 2 \mu \mathrm{m}$ width of the area covered with the imprints.

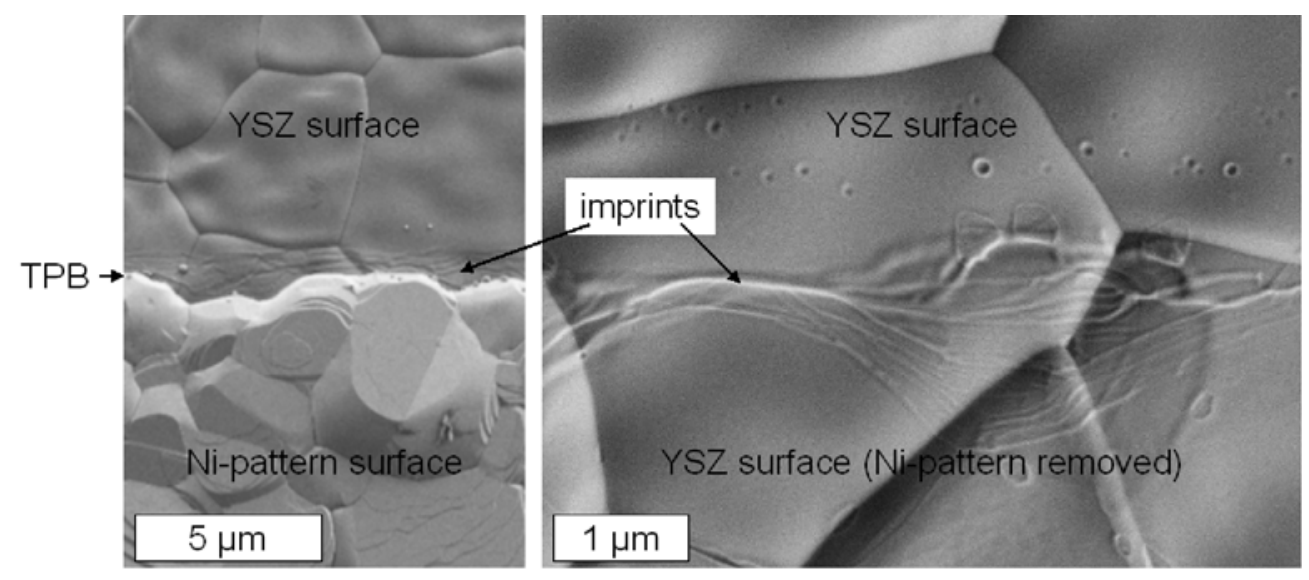

Figure 3. SEM images showing nanoscaled imprints on the electrolyte surface close to the TPB.
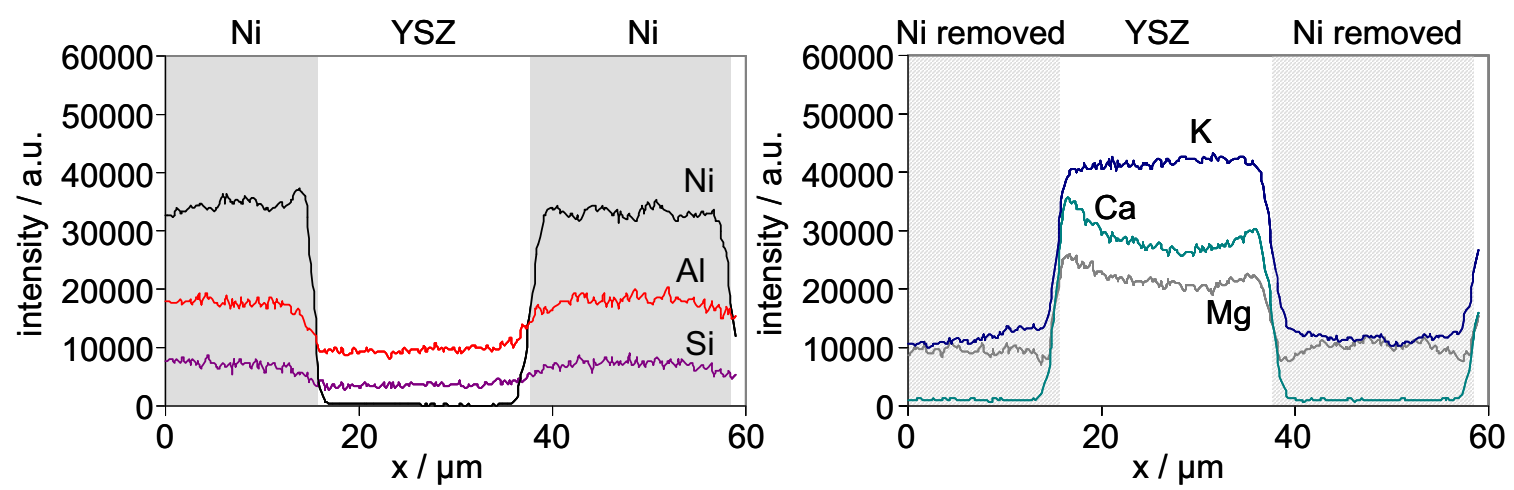

Figure 4. TOF-SIMS intensity profile taken from a $60 \times 60 \mu \mathrm{m}^{2}$ scan of main impurities on the sample with Ni pattern (right) and after removing the Ni-pattern (left). The Ni signal is plotted for comparison.

Whereas TOF-SIMS can not provide accurate information about the concentration of the different impurities, the XPS-analysis showed that the amount of impurities and especially the amount of Si on the surface of the samples in this study is very low (sum of impurities $/ \mathrm{Zr}=0.25-0.28, \mathrm{Si} / \mathrm{Zr}=0.025-0.173)$ compared to values for highly pure point electrodes reported in literature (sum of impurities $/ \mathrm{Zr}=0.54, \mathrm{Si} / \mathrm{Zr}=0.35$ ) (19), (14). Comparing the nominal silica content in the YSZ-substrate $\left(0.032\right.$ wt. $\left.\% \mathrm{SiO}_{2}\right)$ and the $\mathrm{Si} / \mathrm{Zr}$ ratios on the substrate surface of 0.173 (as delivered), 0.118 (after sintering of the counter electrode at $1300^{\circ} \mathrm{C}$ ) and 0.025 (after characterization), it is obvious that the silica is accumulated at the YSZ-surface during high temperature treatment. Despite that the $\mathrm{SiO}_{2}$-content of the Ni-target is 3 times lower $(<0.01 \mathrm{wt} . \%)$, the TOF-SIMS analysis shows a higher amount of silica on the Ni-surface. We assume that the redistribution of impurities during the initial annealing at $800^{\circ} \mathrm{C}$ and the following testing period influences the dynamic change of the $\operatorname{LSR}_{\mathrm{ct}}$ significantly (14). 


\section{Quantum Chemical Calculations}

The low-energy surface reaction pathways for $\mathrm{H}_{2}$ and $\mathrm{CO}$ oxidation at YSZ surface, as obtained in the DFT calculations, are depicted in Figure 5. Both reaction pathways, I and II, lead to the formation of gaseous $\mathrm{H}_{2} \mathrm{O}$ and $\mathrm{CO}_{2}$ products, respectively. $\mathrm{H}_{2} \mathrm{O}$ formation, however, proceeds via $\mathrm{H}_{2}$ dissociative adsorption - resulting in surface $\mathrm{OH}$ species formation - followed by a surface $\mathrm{H}_{2} \mathrm{O}$ formation step (see Figure 5.I, second and third structures) via a Langmuir-Hinshelwood (LH) reaction mechanism. On the other hand, as indicated by the DFT results shown in Figure 5.II (38), in mutual agreement with recent experimental studies (21), gaseous $\mathrm{CO}_{2}$ is formed via an Eley-Rideal mechanism in which a gas phase $\mathrm{CO}$ molecule directly reacts with a surface oxygen atom to form $\mathrm{CO}_{2}$, which then readily desorbs into the gas phase. The activation energies obtained in the DFT calculation were used in the simulation of TPD/TPR spectra measured for $\mathrm{H}_{2}$ and CO oxidation over YSZ (for details see e.g. Ref. (26) and (38)).

I

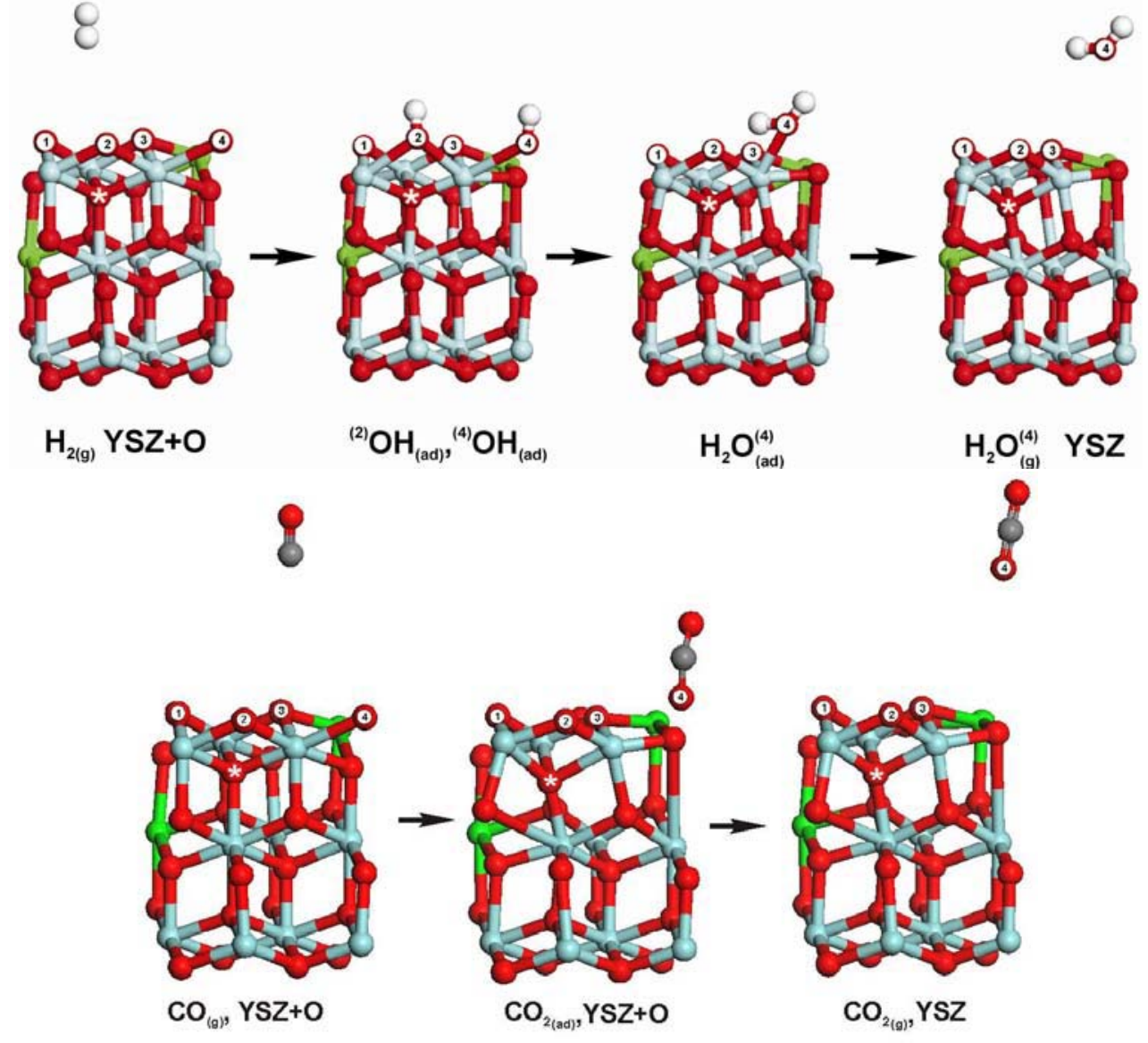

Figure 5. Illustration of surface reaction pathway as obtained in the DFT studies [10] of heterogeneous $\mathrm{H}_{2}$ and $\mathrm{CO}$ oxidation on YSZ surfaces.

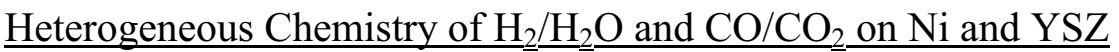

$\mathrm{CO}$ TPD and $\mathrm{CO} / \mathrm{CO}_{2}$ TPR experiments along with numerical simulations allowed to determine quantitative $\mathrm{CO}$ adsorption/desorption and $\mathrm{CO}$ oxidation surface reaction kinetics parameters (21). The CO oxidation studies over YSZ along with DFT calculations revealed that $\mathrm{CO}_{2}$ formation can proceed via a so far unknown Eley-Rideal mechanism where $\mathrm{CO}_{2}$ is formed by direct reaction of gas phase $\mathrm{CO}$ molecules with $\mathrm{O}$ atoms of the YSZ surface. In addition, TPR and TPD studies of $\mathrm{H}_{2}$ oxidation and $\mathrm{H}_{2} \mathrm{O}$ 
dissociative adsorption along with DFT calculations and numerical simulations of the experimental spectra allowed the development of a revised $\mathrm{H}_{2} / \mathrm{H}_{2} \mathrm{O} / \mathrm{YSZ}$ adsorption/desorption and surface reaction mechanism along with the necessary experimentally validated kinetics data set. The experimental studies further demonstrated that during $\mathrm{H}_{2}$ oxidation and $\mathrm{H}_{2} \mathrm{O}$ dissociative adsorption noticeable amounts of $\mathrm{H}_{2} \mathrm{O}$ are "dissolved" in the YSZ bulk, either as interstitial protons (hydrogen) or interstitial OH. The latter result, points towards the possibility of an alternative charge transfer mechanism in the electrochemical $\mathrm{H}_{2}$ oxidation on Ni-pattern/YSZ anodes, which might involve interstitial $\mathrm{OH}$ and/or proton transport through the electrolyte to the $\mathrm{Ni}$ electrode with the actual charge transfer taking place at the Ni-bulk-YSZ-bulk two-phase boundary $(26,39)$.

\section{Elementary Kinetic Modeling of the Electrochemical $\mathrm{H}_{2}$ Oxidation}

Previous studies on model anodes have shown that gas-phase composition and temperature have a strong influence on electrode kinetics (8). Experimental and simulation results of $\mathrm{pH}_{2}, \mathrm{pH}_{2} \mathrm{O}$ and temperature variations are shown in Figure 6 a,b,c. It is obvious that $\mathrm{pH}_{2}$ has only a weak influence on the $\mathrm{LSR}_{\mathrm{ct}}$. Experimentally, it appears that at low $\mathrm{pH}_{2} \mathrm{O}, \mathrm{LSR}_{\mathrm{ct}}$ slightly increases with increasing $\mathrm{pH}_{2}$, while the trend is inverse at higher $\mathrm{pH}_{2} \mathrm{O}$. The simulation is in agreement with the experiment at high $\mathrm{pH}_{2} \mathrm{O}$. Although the slope of the simulation is somewhat smaller for low $\mathrm{pH}_{2} \mathrm{O}$, the experimental trend is not completely reproduced. An increase in $\mathrm{pH}_{2} \mathrm{O}$ strongly enhances electrode performance. The variation of $\mathrm{pH}_{2} \mathrm{O}$ over three orders of magnitude leads to a variation of $\mathrm{LSR}_{\mathrm{ct}}$ of around two orders of magnitude. The simulation is in excellent agreement with the experiment for both $\mathrm{pH}_{2}$ shown. The trend that we observe here was found in the same way in the pattern anode studies of Bieberle et al. (1) and Mizusaki et al. (3); a more detailed comparison is given in (6).

This observed gas-composition dependence of the $\mathrm{LSR}_{\mathrm{ct}}$ is counter-intuitive. Water is a reaction product; according to the principle of Le Chatelier, an increase in product concentration should decrease the reaction rate, while here we observe the opposite. However, the Le Chatelier principle in this simple form is only true for a purely chemical system where reaction rates are indeed only influenced by concentration. In an electrochemical system, such as an SOFC electrode, reaction rates are additionally (and even dominantly) influenced by the electrode potential. A variation in gas-phase composition changes both, the concentrations of the adsorbed intermediates participating in the charge-transfer reaction, and the electrode potential (which can be described by the Nernst equation). The combined concentration and potential changes lead to the observed counter-intuitive change in macroscopic electrode performance which is accurately described by our model. Experimental and simulated LSR $_{\mathrm{ct}}$ values are plotted as a function of temperature in Figure 6c.

In the present experiments, temperature was varied over the wide range of 673-1073 $\mathrm{K}$. Two regimes with slightly different activation energies above and below ca. $950 \mathrm{~K}$ become apparent (cf. also (6)). The simulations are in good agreement with the experiments. The observation of two regimes is reproduced in the simulations, yet the change in activation energy seems to be overpredicted. 
(a)

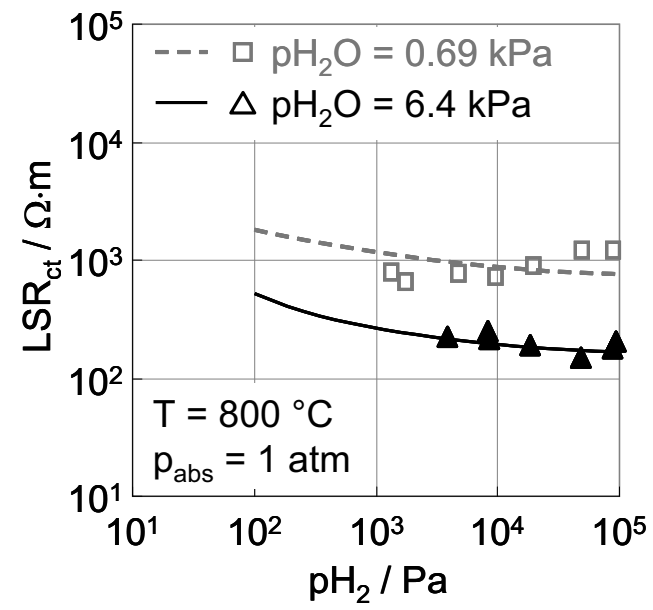

(b)

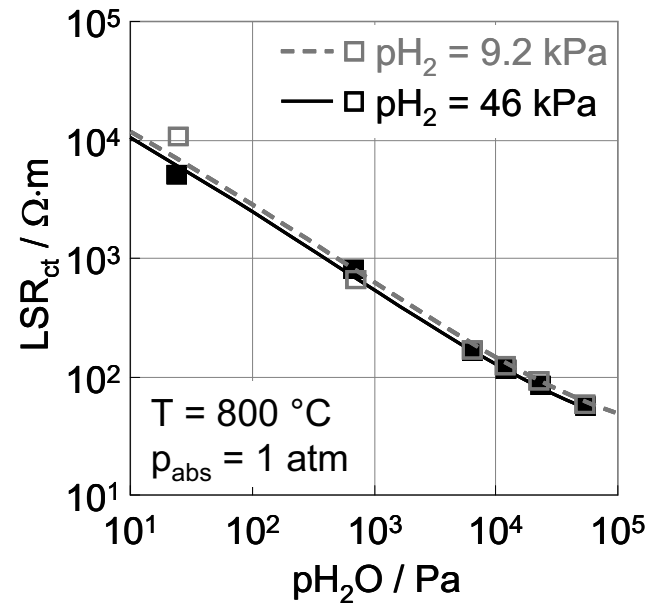

(c)

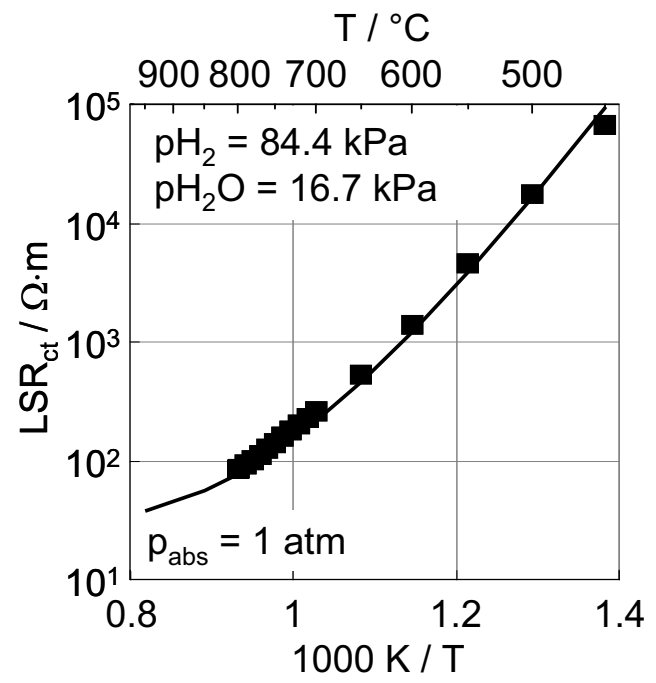

(d)

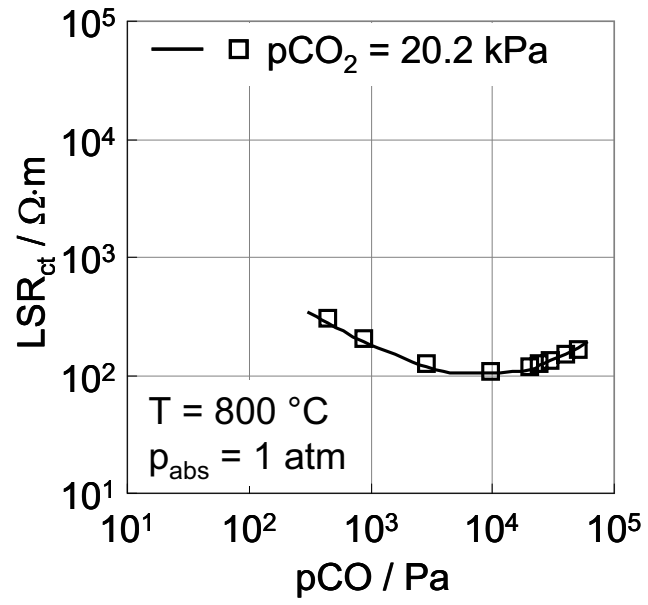

(e)

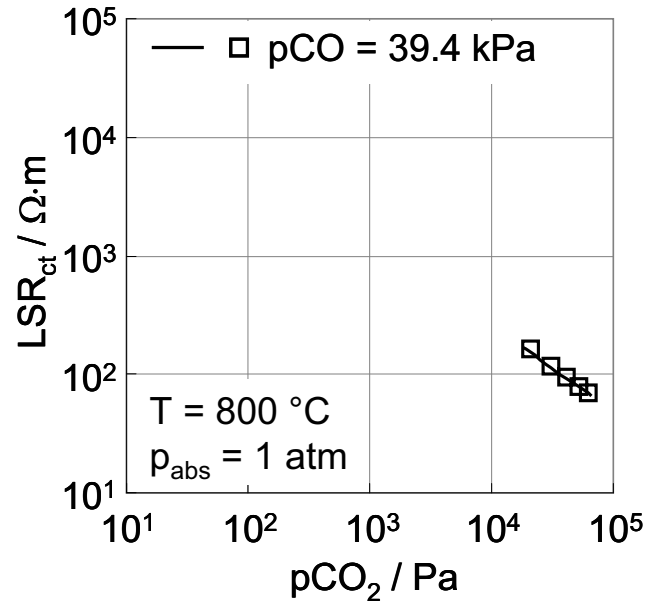

(f)

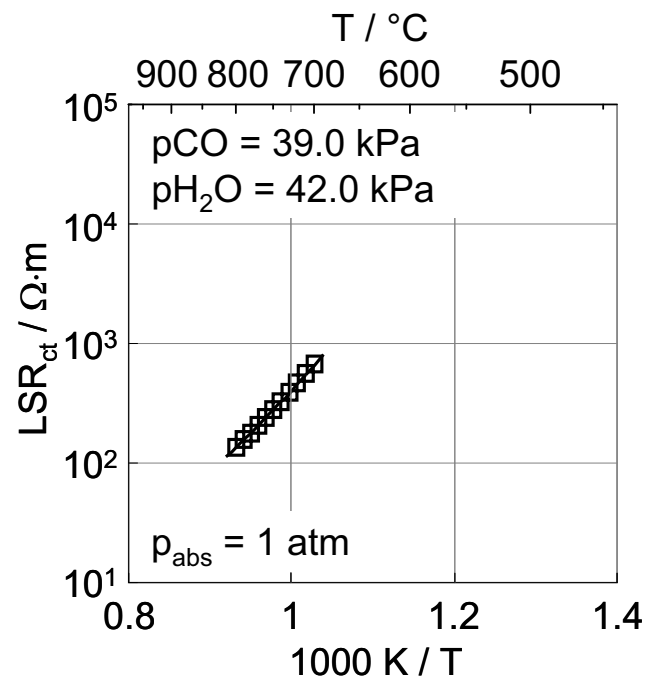

Figure 6. Experimental (symbols) and simulated (lines) line-specific resistance (LSR $\mathrm{Lt}_{\mathrm{ct}}$ ) as a function of partial pressure of oxidizable compounds $\left(\mathrm{H}_{2} / \mathrm{CO}\right)$, reaction products $\left(\mathrm{H}_{2} \mathrm{O}\right.$ $/ \mathrm{CO}_{2}$ ) and temperature. 
In order to further interpret the behavior, a sensitivity analysis was performed for two different temperatures. In such an analysis, model parameters $\mathrm{P}$ are individually varied by $20 \%$, and the impact on the $\mathrm{LSR}_{\mathrm{ct}}$ is quantified as dimensionless relative sensitivity, $\mathrm{s}=$ $\left(\Delta \mathrm{LSR}_{\mathrm{ct}} / \mathrm{LSR}_{\mathrm{ct}}\right) /(\Delta \mathrm{P} / \mathrm{P})$. A sensitivity of unity means that the system's $\mathrm{LSR}_{\mathrm{ct}}$ responds linearly with a change of parameter P. A sensitivity close to zero means that the physical process that is described by the parameter (e.g., diffusion coefficient, rate coefficient) does not influence the $\mathrm{LSR}_{\mathrm{ct}}$ and is therefore not rate-determining. Results for $\mathrm{T}=773 \mathrm{~K}$ and $1173 \mathrm{~K}$ are shown in Figure 7. The data are separated into kinetic parameters of all reactions (pre-exponential factors), transport parameters of all surface-adsorbed species (diffusion coefficients), thermodynamic parameters of selected species (chemical potential) and other parameters (pressure, TPB, temperature). At $773 \mathrm{~K}$, the only ratedetermining reaction is one charge-transfer reaction (spillover of hydrogen from the $\mathrm{Ni}$ surface to hydroxyl ions on the YSZ surface, yielding YSZ-adsorbed $\mathrm{H}_{2} \mathrm{O}$ ). At $1173 \mathrm{~K}$, this reaction is co-limited by the other charge-transfer reaction (spillover of hydrogen from the Ni surface to oxygen ions on the YSZ surface) as well as the water dissociation and water desorption reactions on YSZ. This change in rate-determining steps is the origin of the observed change in activation energy.

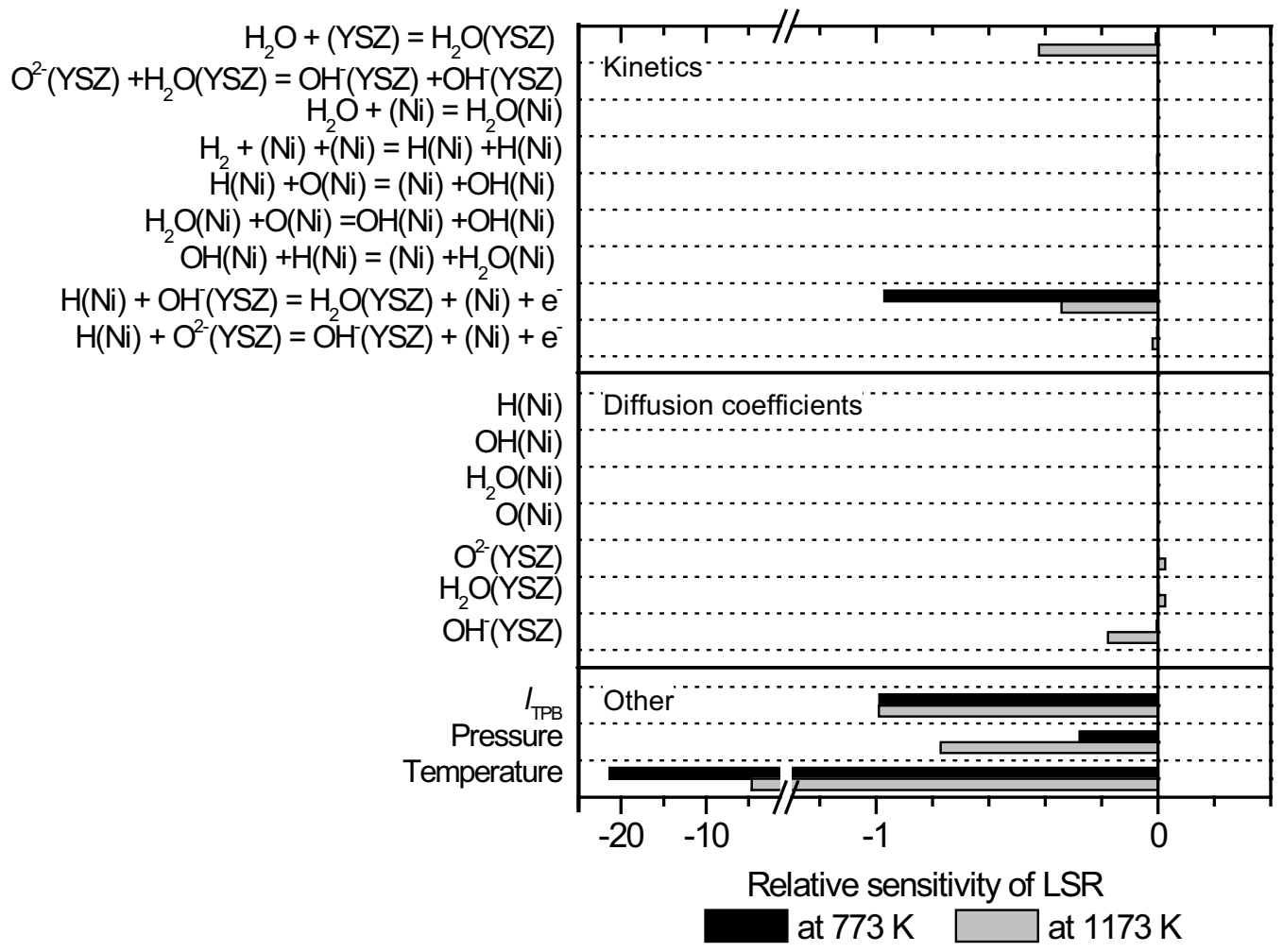

Figure 7. Sensitivity analysis for the pattern anode performance (line-specific resistance) for two different temperatures $\left(\eta=0 \mathrm{~V}, \mathrm{pH}_{2}=8.44 \cdot 10^{4} \mathrm{~Pa}, \mathrm{pH}_{2} \mathrm{O}=1.67 \cdot 10^{4} \mathrm{~Pa}\right)$. A positive value for the sensitivity means that an increase in parameter increases the $\mathrm{LSR}_{\mathrm{ct}}$.

\section{Electrochemical CO Oxidation}

Experimental and simulated $\mathrm{LSR}_{\mathrm{ct}}$ as function of $\mathrm{CO}$ and $\mathrm{CO}_{2}$ partial pressure and temperature in the $\mathrm{CO} / \mathrm{CO}_{2} / \mathrm{N}_{2}$ system is shown in Figure $6 \mathrm{~d}$,e,f. The simulations are based on a reaction mechanism consisting of three distinct CT steps denoted in the following as $\mathrm{O} 1, \mathrm{O} 2$, and $\mathrm{O} 6$ (Figure 1). In the first CT step, an electron is transferred to 
the Ni electrode O1: $\left(\mathrm{O}_{\mathrm{YSZ}}^{2-} \rightleftharpoons \mathrm{O}_{\mathrm{YSZ}}^{1-}+\mathrm{e}_{\mathrm{Ni}}^{-}\right)$. This CT step is followed by two competitive $\mathrm{CT}$ steps $(\mathrm{O} 2$ and $\mathrm{O} 6) . \mathrm{O} 2$ represents an oxygen ion spillover reaction with a simultaneous discharge of the oxygen ion, O2: $\left(\mathrm{O}_{\mathrm{YSZ}}^{1-}+\square_{\mathrm{Ni}} \rightleftharpoons \mathrm{O}_{\mathrm{Ni}}+\square_{\mathrm{YSZ}}+\mathrm{e}_{\mathrm{Ni}}^{-}\right)$, and O6 represents a simple electron transfer step O6: $\left(\mathrm{O}_{\mathrm{YSZ}}^{1-} \rightleftharpoons \mathrm{O}_{\mathrm{YSZ}}+\mathrm{e}_{\mathrm{Ni}}^{-}\right)$in which a YSZ surface oxygen ion transfers an electron to the $\mathrm{Ni}$ electrode. The pronounced minimum in the $\mathrm{CO}$ pressure dependence of the line-specific resistance can be explained in a straightforward way in the framework of this mechanism. In the region of high $\mathrm{CO}$ pressure, the $\mathrm{O} 2 \mathrm{CT}$ step is dominating, with decreasing $\mathrm{CO}$ partial pressure, which results in a pronounced increase of the oxygen coverage of the Ni TPB region, the overall mechanism changes and the $\mathrm{O} 6 \mathrm{CT}$ steps starts to become rate determining (40).

\section{Applicability of Patterned Anode Results in Cermet Anode Models}

One major question concerning model anodes is, if the evaluated $\mathrm{LSR}_{\mathrm{ct}}$ values agree with the $\mathrm{LSR}_{\mathrm{ct}}$ at the TPB in cermet anodes. A first comparison of the electrochemical performance of patterned $\mathrm{Ni}$ anodes and technical $\mathrm{Ni} / 8 \mathrm{YSZ}$ cermet anodes has been performed by a theoretical calculation of the ASR of a cermet anode based on LSR $_{\mathrm{ct}}$ values from patterned $\mathrm{Ni}$ anodes. Using available models as the transmission line model with homogenized electrochemical and transport properties (20) and the space resolved FEM-model with a simplified microstructure (29) good agreement between the performance of a Ni/8YSZ cermet anode and the simulations using the $\mathrm{LSR}_{\mathrm{ct}}$ values obtained with patterned Ni anodes was found (41).

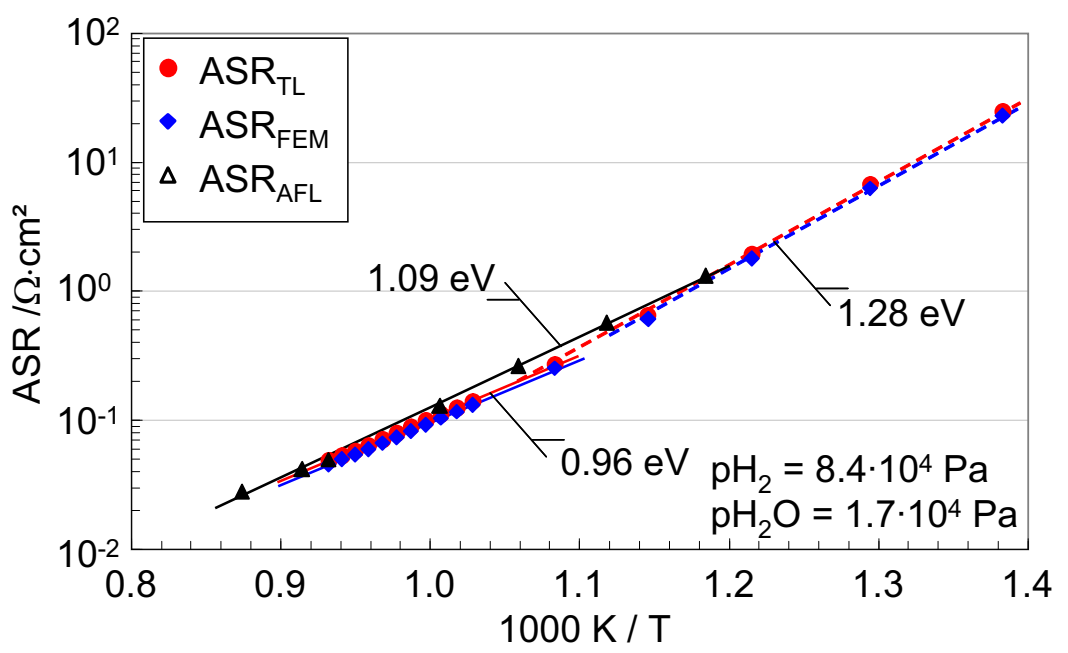

Figure 8. Comparison of results from transmission line calculation $\mathrm{ASR}_{\mathrm{TL}}$ and microstructure simulation $\mathrm{ASR}_{\mathrm{FEM}}$ to $\mathrm{ASR}$ values of the $\mathrm{Ni} / 8 \mathrm{YSZ}$ cermet anode $\mathrm{ASR}_{\mathrm{AFL}}$.

The comparison indicated that in case of $\mathrm{H}_{2}-\mathrm{H}_{2} \mathrm{O}$ similar reaction mechanisms take place in both anode concepts, whereas for $\mathrm{CO}-\mathrm{CO}_{2}$ deviations concerning the $\mathrm{p}\left(\mathrm{CO}_{2}\right)$ dependency were observed. These deviations can be related to a different electrochemical behavior resulting from impurities (14) aging and other dynamic effects as discussed in (6). In comparison with $\mathrm{Ni} / 8 \mathrm{YSZ}$-cermet anodes (32), even microstructurally stable model anodes showed a more distinctive dynamic behavior and an approximately 3 orders of magnitude higher degradation rate $(6,11)$. Further investigations concerning these dynamic processes at model anodes and a comparison with cermet anodes are 
expected to provide a detailed understanding of the degradation processes taking place at the TPB and might even help to predict the long term degradation of cermet anodes.

\section{Conclusions}

The combination of experimental investigations of patterned nickel anodes and modeling provided a profound understanding of the elementary kinetics of the electrooxidation of hydrogen and carbon monoxide at the three phase boundary nickel / $8 Y S Z$ / fuel gas.

The line specific resistance of the three phase boundary was evaluated within a wide range of gas compositions and temperature. The investigations showed that microstructural stability, impurities, accelerated degradation and reversible dynamic changes are key issues which have to be considered. Applying samples and test setups with a sufficient purity as well as appropriate annealing and testing conditions, the line specific resistance can be evaluated with a high reliability.

The comparison of the electrochemical results and elementary kinetic simulations of different spillover scenarios for $\mathrm{H}_{2}$ and $\mathrm{CO}$ oxidation revealed that $\mathrm{H}_{2}$ is primarily electrooxidized via a hydrogen spillover whereas for $\mathrm{CO}$ the electrooxidation occurs via a combined oxygen spillover and reactive electrolyte pathways. For these elementary kinetic mechanisms the models, parameterized with literature data, temperatureprogrammed desorption and reaction and quantum chemical calculation results were in excellent agreement with the experimental data.

For the first time $\mathrm{LSR}_{\mathrm{ct}}$ values evaluated by means of patterned anodes have been applied in homogenized and space resolved models for cermet anodes. The good agreement of modeling and experimental results proved that similar reaction mechanisms take place in both anode concepts and that the results of patterned anode studies can be transferred to cermet anode structures.

\section{Acknowledgments}

Funding of this work was provided by the German Research Foundation (DFG) under grants no. BE 3819/1-1, VO 642/2-1, GE 841/15-1, WE 4188/1-1 and IV 14/16-1. KIT acknowledges further support from the Friedrich-und-Elisabeth-BOYSEN-Stiftung. WGB acknowledges support from the Initiative and Networking Fund of the Helmholtz Association.

\section{References}

1. A. Bieberle et al., J. Electrochem. Soc., 148, A646 (2001).

2. B. de Boer, PhD Thesis, University of Twente, The Netherlands (1998).

3. J. Mizusaki et al., Solid State Ionics, 70, 52 (1994).

4. J. Mizusaki et al., J. Electrochem. Soc., 141, 2129 (1994).

5. A. M. Sukeshini et al., J. Electrochem. Soc., 153, A705 (2006). 
6. A. Utz et al., J. Electrochem. Soc., 157, B920 (2010).

7. A. Leonide et al., Proceedings of the 8th European Solid Oxide Fuel Cell Forum, A0501 (2008).

8. W. G. Bessler et al., Physical Chemistry Chemical Physics, 10.1039/C0CP00541J, 13888 (2010).

9. A. Utz et al., Proceedings of the 9th European Solid Oxide Fuel Cell Forum, 5-91 (2010).

10. F. Z. Boulenouar et al., ECS Trans., 2001, 759 (2001).

11. A. Utz et al., J. Power Sources, 10.1016/j.powsour.2010.10.056 (2010).

12. M. Mogensen et al., in Handbook of Fuel Cells - Fundamentals, Technology and Applications, W. Vielstich, H. Yokokawa, and H. A. Gasteiger (Eds.), p. 543, John Wiley \& Sons Ltd, Chichester (2009).

13. S. B. Adler, J. Electrochem. Soc., 149, E166 (2002).

14. A. Utz et al., Solid State Ionics, accepted for publication, (2010).

15. M. Shishkin et al., Journal of Physical Chemistry C, 113 (2009).

16. S. B. Adler et al., 5 ed., W. Vielstich, H. Yokokawa, and H. A. Gasteiger (Eds.), John Wiley \& Sons, Chichester, UK (2009).

17. A. Utz et al., Solid State Ionics, accepted for publication, (2010).

18. H. Störmer et al., Proceedings of the 9th European Solid Oxide Fuel Cell Forum, 5-122 (2010).

19. K. Norrman et al., Journal of the European Ceramic Society, 26, 967 (2006).

20. V. Sonn et al., J. Electrochem. Soc., 155, B675 (2008).

21. V. Yurkiv et al., J. Electrochem. Soc., 158 (2010).

22. M. D. Segall et al., J Phys-Condens Mat, 14 (2002).

23. J. P. Perdew et al., Phys Rev B, 46 (1992).

24. D. Vanderbilt, Phys Rev B, 41 (1990).

25. H. J. Monkhorst et al., Phys. Rev. B, 13 (1976).

26. A. Gorski et al., J. Power Sources, in press (2010).

27. M. Vogler et al., J. Electrochem. Soc., 156, B663 (2009).

28. W. G. Bessler et al., Electrochim. Acta, 53 (2007).

29. B. Rüger et al., Proceedings of the 7th European Solid Oxide Fuel Cell Forum, B075 (2006).

30. A. Ehn et al., J. Electrochem. Soc., 157, B1588 (2010).

31. A. Utz et al., ECS Trans., 25, 2013 (2009).

32. C. Endler et al., J. Electrochem. Soc., 157, B292 (2010).

33. A. Leonide et al., J. Electrochem. Soc., 155, B36 (2008).

34. A. Leonide et al., J. Power Sources, in press (2011).

35. R. J. Aaberg et al., Proceedings of the 17th Risoe International Symposium on Materials Science: High Temperature Electrochemistry: Ceramics and Metals, 511 (1996).

36. P. Holtappels et al., Journal of Applied Electrochemistry, 29, 561 (1999).

37. K. V. Jensen et al., Solid State Ionics, 160, 27 (2003).

38. A. Gorski et al., ECS Trans. (2011).

39. M. Vogler et al., ECS Trans., 25 (2009).

40. V. Yurkiv et al., these proceedings, (2011).

41. A. Utz et al., these proceedings, (2011). 